\title{
THE EFFECTS OF RESERPINE ON HYPERTENSIVE PATIENTS OVER A PERIOD OF TWO YEARS
}

BY

\author{
ROBERT HODGKINSON
}

\author{
From the West Middlesex Hospital, Isleworth
}

Received November 22, 1955

To justify the use of a drug in the routine treatment of hypertension it should be capable of reducing the diastolic and systolic blood pressures by $20 \mathrm{~mm}$. $\mathrm{Hg}$ or more throughout the day and tolerance to its action should not develop on prolonged administration; the therapeutic dose should be considerably less than the toxic dose and since indefinite administration is required, the sideeffects should not interfere with either the patient's capacity for work or his enjoyment of life. It was the purpose of this study to determine how far these requirements are fulfilled by reserpine, a pure crystalline alkaloid obtained from Rauwolfia serpentina.

Reserpine was isolated by Muller et al. (1952) from Rauwolfia serpentina and pharmacological studies have been published by a number of investigators. Bein et al. (1953) stated that its activity on experimental animals is characterized by sedation and hypnosis, a lowering of the blood pressure, a reduction in respiratory volume, bradycardia, miosis, increased intestinal activity, and a lowering of body temperature. The sedative action chiefly affects the motor cortex and inhibits the stimulant action of caffeine. The mode and site of action of reserpine is not known but animal and clinical studies suggest that its action is on the central nervous system (Winsor, 1954). Plummer et al. (1954) consider that the most likely area at which the drug could bring about the observed alteration in autonomic balance is in the hypothalamic region.

Trappold et al. (1954) examined the cardiovascular and respiratory effects of reserpine in the dog; their evidence suggests that the hypotensive action is due to an inhibition of nerve impulses through or from a higher brain centre, such as the hypothalamus. Chen et al. (1954) showed that reserpine may cause an increase in excitability or conductivity of parts of the central nervous system. From a later paper (Chen et al., 1954) it appears that the antagonism between reserpine and epanutin is competitive in nature, a facilitatory and an inhibitory effect respectively acting on the spread of the seizure discharge.

\section{MATERIALS AND Methods}

Thirty-five hypertensive patients were chosen for this study. One was excluded from the analysis of results, as treatment had to be discontinued after 12 weeks' reserpine therapy owing to the development of a state of extreme depression. The criteria for inclusion were capability of treatment on an out-patient basis, an average blood pressure of greater than $150 / 100 \mathrm{~mm}$. mercury and/or a mean blood pressure (diastolic $+1 / 3$ pulse pressure) of $115 \mathrm{~mm}$. mercury. Otherwise there was no selection. Patients were asked to report to the clinic as frequently as possible. For most patients this was every two weeks, although there was a variation from one to four weeks.

The trial of reserpine was planned so that inert tablets were administered to patients for from six to nine months (observation period), reserpine tablets in a dose of one to two milligrams daily were then administered for 12 months (therapeutic period) and finally, patients were divided into two groups, one of which 


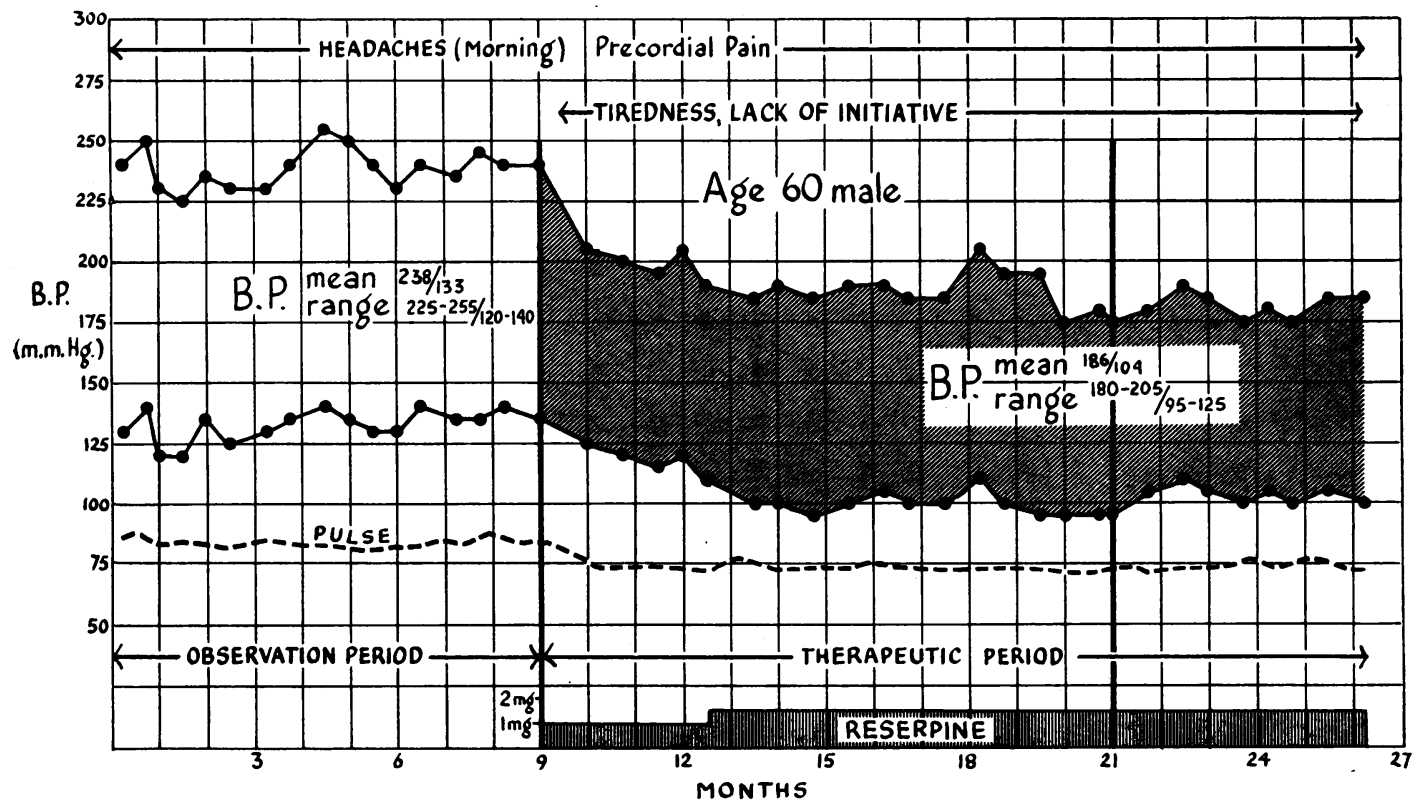

Fig. 1.-The variations in the blood pressure, pulse rate, and symptomatology of a patient over a period of 26 months. Reserpine was administered from the ninth to twenty-sixth month.

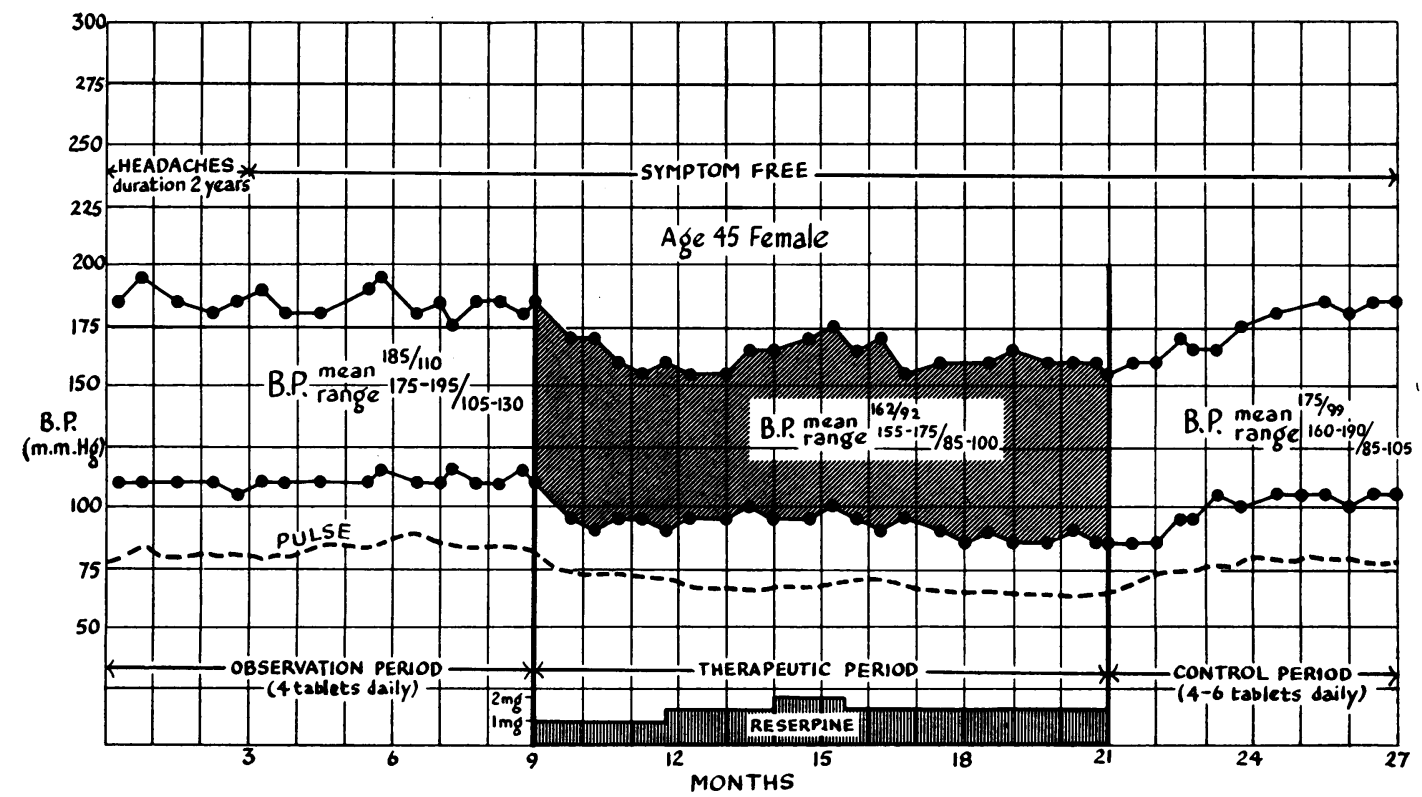

FIG. 2.-The variations in the blood pressure, pulse rate, and symptomatology of a patient over a period of 27 months. Reserpine was administered from the ninth to twenty-first month. 
received reserpine and the other inactive tablets for a further 3 to 6 months (control period). During the control period neither physician nor patient knew which were inert and which were reserpine tablets; the tablets were identical in appearance.

All blood pressure readings were made by the same physician. Three readings were taken during each clinical interview, according to a set routine which included a period of rest and the lowest of the three readings was used in the assessment of results. By this means it was hoped to obtain a figure approximate to the resting blood pressure. Blood pressures were taken in sitting, standing, and supine positions for the first six months of the observation and treatment periods, but as there was no material difference between the values obtained this procedure was replaced later by three blood pressures taken in the sitting position. Blood pressure readings were also made on 20 patients at 15 -minute intervals for a period of two hours, whilst they were receiving control medication or reserpine, in order to determine whether there was any difference between the lowest reading obtained and that obtained by the lowest of three readings, using a fixed routine. Although the blood pressure fluctuated over the two-hour period there was no material difference in the lowest reading taken by that method and the lowest of a set of three.

Symptoms were assessed at regular intervals throughout the trial. A comprehensive list of possible symptoms was tabulated during the planning of the trial and whether a patient was suffering from these or other symptoms was decided by means of indirect questioning. Questions on the number of colds contracted by a patient, his approach to work or recreation were posed at regular intervals with the intention of determining whether the patient had nasal congestion, lack of initiative, or other adverse effects from the treatment.

\section{RESULTS}

Effect on Blood Pressure. The effect of reserpine on the blood pressure in individual patients was tabulated and a summary of the effect on all patients is shown in Table $I$, which gives the change in blood pressure during the " observation" as compared with the "therapeutic" period.

TABLE I

A Comparison of the Mean Blood Pressure for all Patients in the Observation, Therapeutic, and Control Periods

\begin{tabular}{|c|c|c|c|c|c|c|c|}
\hline & & \multirow[b]{2}{*}{$\begin{array}{l}\text { No. of } \\
\text { Patients }\end{array}$} & \multicolumn{3}{|c|}{ Mean B.P. in } & \multirow[b]{2}{*}{$\begin{array}{l}\text { Difference between } \\
\text { (B) and (A) }\end{array}$} & \multirow[b]{2}{*}{$\begin{array}{l}\text { Difference between } \\
\text { (C) and (B) }\end{array}$} \\
\hline & & & $\begin{array}{l}\text { Obser- } \\
\text { vation } \\
\text { period } \\
\text { (A) }\end{array}$ & $\begin{array}{l}\text { Thera- } \\
\text { peutic } \\
\text { period } \\
\text { (B) }\end{array}$ & 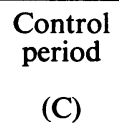 & & \\
\hline \multirow{2}{*}{ Group } & Systolic & 16 & 210 & 195 & 193 & $\begin{array}{c}-15^{* *} \\
(\mathrm{t}=-4 \cdot 07, \text { d.f. }=15)\end{array}$ & $(t=1 \cdot 3$ d.f. $=15)$ \\
\hline & Diastolic & 16 & 125 & 111 & 111 & $(\mathrm{t}=-5 \cdot 09$, d.f. $=15)$ & $\left(\mathrm{t}=-0 \cdot 25^{*}\right.$ d.f. $\left.=15\right)$ \\
\hline \multirow{2}{*}{$\begin{array}{c}\text { Group } \\
2\end{array}$} & Systolic & 18 & 213 & 194 & 209 & $\begin{array}{c}-19 * * * \\
(\mathrm{t}=-4 \cdot 46, \mathrm{~d} . \mathrm{f} .=17)\end{array}$ & $\begin{array}{c}+15 * * * \\
(\mathrm{t}=5 \cdot 11, \text { d.f. }=17)\end{array}$ \\
\hline & Diastolic & 18 & 124 & 108 & 119 & $\begin{array}{c}-16^{* * *} \\
(\mathrm{t}=-6 \cdot 49, \mathrm{~d} . \mathrm{f} .=17)\end{array}$ & $\begin{array}{c}+11^{* * *} \\
(\mathrm{t}=4 \cdot 9, \text { d.f. }=17)\end{array}$ \\
\hline
\end{tabular}

Changes in Symptoms during the Observation, Therapeutic, and Control Periods. All symptoms found in patients during observation, therapeutic, and control periods were recorded and the following changes were observed: about one-third described a feeling of calmness or wellbeing during reserpine therapy, but the advantage of this was partly offset by a feeling of tiredness, loss of energy, lack of initiative and depression, in an approximately equal number of patients. A gain in appetite and weight, nasal congestion and nightmares were commonly complained of during treatment. Although anginal and præcordial pain showed no change in frequency during the trial, the 
intensity appeared less. The frequency of headaches decreased during the observation period, and further during reserpine therapy. Other symptoms remained largely unaltered.

The most troublesome side-effects were tiredness and nasal congestion, and the most serious was depression. One patient who was excluded from the analysis of results developed extreme depression after three months' therapy.

Case Record 101. A man of 54 had a blood pressure of 180/110 consistently during the observation period, and his behaviour was normal. The patient stated that he had never previously had a period of depression, nor psychiatric treatment. After receiving reserpine $1 \mathrm{mg}$. daily for 12 weeks he complained of depression. He continued with treatment for a further week, during which time the depression increased, and he became worried regarding the possibility of his having cancer. Treatment was discontinued and he was reassured. It was pointed out to him that his weight was increasing and a number of examinations were performed to convince him that his complaint was not cancer. For the next two weeks, according to his wife, he cried continually day and night, slept little, and on two occasions sent for his family doctor during the early hours of the morning. He was reassured repeatedly by his wife, who was a nurse, and by his family doctor, but it was impossible to placate him. After a further week (three weeks without therapy) his behaviour was normal and he stated he felt fit to start work again.

Effects on Retina, Electrocardiogram, and X-ray Appearances. No changes were found which could be attributed to the reserpine.

Effect on Pulse Rate. The pulse rate was slowed in all the patients during reserpine therapy. The mean reduction was 15 (range 3 to 32). There was no relationship between the changes in blood pressure and the reduction in the pulse rate.

\section{Discussion}

In view of the delayed effect of reserpine therapy and the occurrence of spontaneous variations in the blood pressure, it was felt that a test of statistical significance should be applied to determine whether the results could be attributed to chance. Comparison of the differences in mean blood pressure for all patients in the therapeutic and observation periods (Table I) shows that the possibilities of the results occurring by chance were less than 1 in 100 for the systolic pressure in Group 1 , and less than 1 in 1000 for the diastolic pressure in Group 1, and for the systolic and diastolic pressures in Group 2. In Group 1 where reserpine was administered in both control and therapeutic periods, $p$ was greater than 0.2 for the systolic and greater than 0.8 for the diastolic. This may therefore be considered as a chance variation. In Group 2 (in which inert tablets were administered in the control period) the difference between the control and therapeutic periods in regard to the systolic and diastolic pressures was such that the possibility of this being a chance finding were less than 1 in 1000 .

The average reduction in the blood pressure following reserpine for all 34 patients was $18 \mathrm{~mm}$. $\mathrm{Hg}$ in the systolic and $15 \mathrm{~mm}$. in the diastolic when the findings for the observation and therapeutic periods are compared. Approximately 40 per cent of patients showed a reduction of $20 \mathrm{~mm}$. $\mathrm{Hg}$ or over in the systolic and diastolic pressures (Table II). These findings agree substantially with those of other workers. Hughes et al. (1954) treated 62 unselected hypertensive patients with an average daily dose of 3 or $4 \mathrm{mg}$. of reserpine. Thirty-three showed a fall in blood pressure of over $20 \mathrm{~mm}$. $\mathrm{Hg}$ in both the systolic and diastolic pressures. Of 28 cases with a diastolic pressure between 100 and $120 \mathrm{~mm}$. before treatment, 13 showed an average mean fall in systolic pressure of $29 \mathrm{~mm} . \mathrm{Hg}$ and $18 \mathrm{~mm}$. $\mathrm{Hg}$ in diastolic pressure. In the 15 cases that did not respond the average mean fall in systolic and diastolic pressures was only $8 \mathrm{~mm}$. $\mathrm{Hg}$. Of a second group of 34 patients having diastolic pressure of over $120 \mathrm{~mm}$. of mercury, 20 responded favourably, the average mean fall being from $220 / 132 \mathrm{~mm}$. to $193 / 108 \mathrm{~mm}$. $\mathrm{Hg}$, while the remaining 14 cases showed practically no change in the blood pressure. A beneficial effect following the use of reserpine was noted by Hensler (1953) in 13 of 18 cases of essential hypertension, whilst 3 of 13 other non-renal cases showed hypotensive changes. Doyle and Smirk (1954) used 6 to $9 \mathrm{mg}$. of reserpine daily, and 
TABLE II

Summary of Response of Thirty-Four Patients to Reserpine

\begin{tabular}{|c|c|c|c|c|}
\hline $\begin{array}{l}\text { Pressure response } \\
\quad(\mathrm{mm} . \mathrm{Hg})\end{array}$ & \multicolumn{2}{|c|}{$\begin{array}{l}\text { Number of patients } \\
\text { showing charge in } \\
\text { systolic pressure }\end{array}$} & \multicolumn{2}{|c|}{$\begin{array}{l}\text { Number of patients } \\
\text { showing change in } \\
\text { diastolic pressure }\end{array}$} \\
\hline $\begin{array}{l}\text { No change }(+10 \text { to }-9) \\
-10 \text { to }-19\end{array}$ & $\begin{array}{r}11 \\
9\end{array}$ & 20 & $\begin{array}{r}8 \\
11\end{array}$ & 19 \\
\hline $\begin{array}{l}-20 \text { to }-29 \\
-30 \text { to }-39 \\
\text { over }-40\end{array}$ & $\begin{array}{l}8 \\
2 \\
4\end{array}$ & 14 & $\begin{array}{r}13 \\
2\end{array}$ & 15 \\
\hline
\end{tabular}

found considerable falls of both systolic and diastolic blood pressures which occurred in the first or second day of treatment, and often persisted for 24 hours after treatment ceased. Wilkins $e t$ al. (1954) found that the average blood pressure of 58 cases of hypertension fell from 191/109 before treatment to $167 / 94$ after treatment.

Tolerance to the hypotensive effect of reserpine did not develop. This can be seen in Fig. 2, in which the blood pressure changes of a patient are shown over a period of two years. This sustained action is also demonstrated by the fact that although the average blood pressure rose almost to the level found in the observation period for those patients receiving inert tablets in the control period, little change was found in the mean blood pressure between the therapeutic and control periods of those receiving reserpine tablets in both. It would seem, therefore, that little tolerance occurs in the period of 12 to 18 months' continuous reserpine therapy.

Side-effects, particularly lack of initiative, tiredness, and lack of vitality, occurred to a degree that would make reserpine therapy unsuitable for continuous administration in some patients. Only one severe case of depression was found in this series. No tolerance of these side-effects developed after the first two weeks of therapy in which tiredness was a common symptom.

It may be concluded that reserpine is a valuable drug in the treatment of some cases of hypertension. It has the advantage of having a less violent and more prolonged action than hexamethonium and tolerance does not seem to develop on continuous administration. Adverse features are that it does not act in all patients, and that its hypotensive effect is relatively small. While side-effects are not marked, care must be taken not to make the life of patients miserable because of lack of vitality in return for the unproven value of reducing the blood pressure. The physician must be on the alert for the onset of extreme depression and mental disturbance.

\section{SUMMARY}

Reserpine in a dose of one to two mg. daily was administered to 34 hypertensive patients for a period of twelve to eighteen months. One additional patient was not considered in the results as therapy had to be stopped after three months owing to the onset of extreme depression.

Approximately 40 per cent of patients showed a hypotensive effect of over $20 \mathrm{~mm}$. Hg. The average reduction in the blood pressure for all patients was $18 / 15 \mathrm{~mm} . \mathrm{Hg}$.

No tolerance to the hypotensive effect of reserpine was noted over a period of twelve to eighteen months. Side-effects such as lack of initiative and tiredness may make reserpine unsuitable for indefinite administration in some patients. The physician must watch for the possible development of depression or other mental disturbances in some patients.

I am grateful for the assistance and encouragement given to me by Dr. M. M. Deane and Dr. H. W. Pearson, to Dr. J. Knowlden for statistical advice and help in analysing the case records, and to Miss D. Lacey for compiling and typing tables and manuscripts. The reserpine used in this trail was donated by the research division of Parke Davis \& Co. Ltd. 


\section{REFERENCES}

Bein, H. J., Gross, F., Tripod, J., and Meier, R. (1953). Schweiz. med. Woch., 83, 1007.

Chen, G., and Ensor, C. R. (1954). Proc. Soc. exper. Biol. N.Y., 87, 602.

- _ and Brohmer, B. (1954). Proc. Soc. exper. Biol., N.Y., 86, 507.

Doyle, A. E., and Smirk, F. H. (1954). Lancet, 1, 1096, 1097.

Hensler, L. (1953). Schweiz., med. Wschr., 83, 1162-1166.

Hughes, W., Dennis, E., McConn, R., Ford, R., and Moyer, J. H. (1954). Amer. J. med. Sci., 228, $21-35$.

Muller, J. M., Schlittler, E., and Bein, H. J. (1952). Experienta, 8, 338.

Plummer, A. J., Barret, W. E., Wagle, G., and Yonkman, F. (1954). Federation Proc., $12,357$.

Trappold, J. H., Plummer, A. J., and Yonkman, F. F. (1954). J. Pharmac., 110, 205.

Wilkins, R. W., Judson, W. E., Stone, R. W., Hollander, W., Huckabee, W. E., and Friedman, I. W. (1954). New Eng. J. Med., 250, 477.

Winsor, T. (1954). N.Y. Acad. Sci., 59, 61. 